\title{
Measuring Community Participation Among Japanese with Serious Mental Illnesses
}

\author{
Shinichi Nagata $(\mathbb{D} \cdot$ Jun Yaeda $\cdot$ Eugene Brusilovskiy $\cdot$ Koji Ota $\cdot$ \\ Sanae Tsumuraya $\cdot$ Fumie Hisanaga $\cdot$ Yoshiyuki Tobita $\cdot$ Mark S. Salzer
}

Received: 24 November 2021 / Accepted: 21 January 2022 / Published online: 23 February 2022

(C) The Author(s), under exclusive licence to Springer Nature India Private Limited 2022

\begin{abstract}
Community participation is associated with physical, cognitive, and mental health benefits for people with serious mental illnesses (SMI) and is recognized as a critical component of health functioning. Developing reliable measurement of participation in different cultural contexts and languages is important to expanding knowledge in this area. The aim of this study was to translate a psychometrically sound English-language community participation measure into Japanese and examine its test-reliability with a
\end{abstract}

S. Nagata $(\bowtie)$

Faculty of Health and Sport Sciences, University of Tsukuba, Tsukuba, Japan

e-mail: nagata.shinichi.gm@u.tsukuba.ac.jp

J. Yaeda $\cdot$ S. Tsumuraya

Faculty of Human Sciences, University of Tsukuba,

Tokyo, Japan

E. Brusilovskiy · M. S. Salzer

Department of Social and Behavioral Sciences, Temple

University, Philadelphia, USA

K. Ota

College of Education, Tamagawa University, Tokyo, Japan

F. Hisanaga

Community Mental Health and Welfare Bonding

Organization, Ichikawa, Japan

Y. Tobita

Faculty of Social Welfare, Shizuoka University of

Welfare, Shizuoka, Japan population of Japanese people with SMI. Self-reported data were gathered twice from 253 individuals within $48 \mathrm{~h}$ using the Temple University Community Participation-Japanese version (TUCP-J) at Type-B Continuous Employment Support Centers in Japan between November 2020 and February 2021. Participant responses were similar on four of the five participation subscales. At the item-level, participants provided consistent responses on 26 out of 27 of the items about amount of participation and had high itemlevel concordance (77-93\%) on their ratings of the importance (Yes; No) of each participation activity and their reported participation sufficiency (Enough; Not Enough; Too Much: 73-88\%). Overall, the results demonstrated strong evidence of test-retest reliability of the TUCP-J and identified a number of areas that were important to respondents, but where they were reporting not doing enough.

Keywords Community inclusion - Participation · Measurement $\cdot$ Serious mental illness $\cdot$ Reliability

\section{Introduction}

The United Nations Convention on the Rights of People with Disabilities identified community inclusion, understood as the opportunity for full participation in meaningful activities, as a basic human right [1]. This declaration acknowledges the long-history of 
marginalization and exclusion of people with disabilities, including those with serious mental illnesses, and calls for nations around the world to engage in efforts that promote participation as a moral responsibility. More than 180 countries around the globe, including Japan, have ratified the treaty.

Community inclusion, and the increased participation in society that results, such as greater employment, educational attainment, engagement in faith communities, and better relationships with friends and family, is also a medical necessity in the sense that such participation is associated with greater physical, cognitive, and mental health and wellness $[2,3]$. The World Health Organization's (WHO) International Classification of Functioning, Disability, and Health [4] has conceptualized participation as a key component of health. For example, people with serious mental illnesses who participate more experience greater levels of recovery and subjective well-being [5, 6], elevated levels of physical activity [7], and experience physical and cognitive health benefits, as well as reduced depression as a result [2, 8-10]. Moreover, participation can expand social networks and deepen social connectedness [11, 12], which are at the core of well-being [13-15]. Unfortunately, a report from the World Health Organization [16] concludes that few advances have been made in increasing community participation among people with SMI, which is consistent with research demonstrating that people with SMI lag well behind the general population in terms of amount, breadth, and sufficiency of participation [17].

Community participation of people with SMI is increasingly viewed as important in Japan. Unlike other developed countries, Japanese mental health systems have focused primarily on symptom reduction and maintenance, including heavy dependence on inpatient care, until relatively recently [18]. In 2004, the Japanese government initiated policies that emphasized deinstitutionalization and community living [19], which aligned with findings that Japanese citizens with SMI strongly desire opportunities for meaningful lives in their community [20, 21]. A number of participation-oriented intervention models have since been implemented in Japan and found to be effective, such as Individualized Placement and Support (IPS) [22, 23], assertive community treatment (ACT) $[24,25]$, and peer support [26].
Effective systems transformation requires robust measures of participation $[27,28]$ that are reliable in different cultural contexts. Such a measure in Japanese has not yet been established [19]. The aim of this study is to examine whether a measure of participation that was developed in the United States can reliably assess community participation among a Japanese psychiatric population. The Temple University Community Participation measure [29] was selected because it has a number of important characteristics. It involved input from individuals with significant mental health issues and examines a broad-range of participation areas (e.g., work, education, faith, leisure, social relationships, online activities, volunteering, etc.). It also incorporates a self-determination framework whereby participation is assessed within the context of an individual's desires [30], including an assessment of whether a person views each area of participation as important to them and the extent to which they believe they have engaged in the activity enough. The original English-language version also has good evidence of reliability [27, 29] and validity [5, 17] with an SMI population.

\section{Method}

Measures

\section{Temple University Community Participation Measure}

This study utilizes the Temple University Community Participation measure (TUCP) that was slightly modified to be more consistent with the WHO's International Classification of Functioning, Disability, and Health framework ${ }^{1}$ and separately measure participation with family members versus friends, partly in order to be more sensitive to possible cultural differences in the roles these relationships play in the lives of people around the world. The TUCP examines participation in 27 areas of the participation-related life domains identified in the International Classification of Functioning, Disability, and Health [4]: major life areas (e.g., work, education), community, social,

\footnotetext{
1 "Engaging in organized sport" and "socializing with people from work, school, neighborhood, or other acquaintances" were added because the ICF includes sport and informal social relationship as important participation areas.
} 
and civic life (e.g., faith, leisure, volunteering), and interpersonal relationships (e.g., family, friends). A full list of items is presented in a later table. Participants report the number of days in the past 30 days they participated in each area without the help of mental health staff, whether they did the activity as much as they desired, with response options of "enough," "not enough," or "too much," and whether the activity was important to them. Five participation constructs were examined in the current study.

Participation Amount Sum of participation days reported across the 27 activity areas. The possible scores can range between 0 and 810 (27 areas of activities $\times 30$ days).

Number of Important Activity Areas Sum of the number of activities indicated as important to the participant. This construct assesses the breadth of interests the individuals has. The possible scores can range between 0 and 27 .

Breadth of Participation Sum of the number of important areas the person identified where they participated at least one day. This construct indicates the variety of areas that a person is engaging in to some degree. The score of Breadth can range between 0 and 27.

Breadth Ratio Calculated as a ratio of the number of important areas identified by the person that were done at least one day over the total number of important areas identified by the person. For example, if a person had 12 important areas and engaged in six areas then their Breadth Ratio would be 0.50 or $50 \%$ (e.g., 6/12). Higher scores indicate broader engagement in important areas. Breadth Ratio can range between 0 and 1.00 .

Participation Sufficiency Participation Sufficiency assesses the degree to which individuals report doing "enough" in areas identified as important to them. It is calculated as a ratio of the number of important areas they identify as being done enough over the total number of important areas they identify. For example, if a person indicated having 12 important areas and reported participating "enough" in four areas then their Sufficiency score is 0.33 or $33 \%$ (e.g., 4/12). Higher scores reflect a higher proportion of important areas where they feel they do enough.

\section{Demographic Variables}

Gender, age category (i.e., 20-29, 30-39, 40-49, etc.), how often they were involved in the CESC, and the amount of money they had to engage in communitybased activities were included in the survey.

\section{Translation Procedures}

A two-step translation procedure involving backtranslation and assessment of cross-cultural equivalence was used. The back translation procedure [31] involved three individuals. First, a Japanese scholar who earned a Master's and Ph.D. degrees in the United States and had approximately ten years of work experience in the country translated the English version into Japanese. Second, a Japanese mental health professional who had studied and earned a master's degree in the United States translated the Japanese version back to English. Finally, an Englishspeaking scholar who was involved in the development of the measure verified the back-translated English-version. Cross-cultural equivalence was assessed by two individuals who had experience working with mental health service consumers in the United States and Japan who reviewed each item to ensure that the Japanese version was consistent with the intent of the English version. Finally, the five Japanese mental health service consumers reviewed the measure, which resulted in slight additional modifications.

\section{Participants}

Study participants were recruited from 17 Continuous Employment Support Centers in Japan between November 2020 and February 2021. Inclusion criteria included (a) using a service at a Type-B Continuous Employment Support Center (CESC: Ministry of Health, Labor, and Welfare, 2013 [32]), and either (b-1) possessing a psychiatric disability certificate endorsed by a psychiatrist and issued by a municipality or (b-2) having a diagnosis of psychiatric disorder. Those who use a Type-B CESC service have considered to have severe disability because its eligibility requirements include the use of an assistance for activities of daily living, or the identified critical problems for seeking employment confirmed by a transitional employment service provider. Those who 
are more able are typically be placed in a Type-A CESC or a transitional employment support service. Type-B CESCs are categorized as a social welfare service in the domain of employment. It is not a competitive employment, and there is no labor contract involved as the work is regarded as a job training service. Type-B CESCs are similar to sheltered employment programs and are often private companies and businesses that are certified by prefectures of Japan. Type-B CESCs provide entry-level, low intensity work experiences for those who have significant impairments. Service users work part-time and are paid for their labor.

\section{Data Collection Procedures}

Data were collected by staff mental health professional (e.g., a certified psychiatric social worker or a mental health counselor) at each Type-B CESC who had previously established rapport with their clients. Staff received written and verbal instructions for conducting the data collection. Program participants were informed about the opportunity to participate in the study by CESC staff and those who were interested in participating reviewed an informed consent form and provided written consent to participate and consent to publish. The participant then completed the TUCP (i.e., Time 1 survey) and demographic questions with staff support. They completed the TUCP a second time within 48 h (i.e., Time 2 survey) with the support of the same staff at Time 1 . We chose to do the 48-h interval because it is a reasonable compromise between recall bias and unwanted change in behavior [33], considering the TUCP requires a 30-day recall. The research protocol was approved by the Institutional Review Board at the lead author's university (Protocol \# East 2020-82).

A total of 358 individuals were informed about the study and 259 provided informed consent $(72 \%$ of those approached) and completed the measures at Time 1. Six participants were absent due to sickness and could not make it to the Time 2 assessment. But the rest of the participants $(n=253)$ completed the TUCP at Time 2, which is the final sample for this study.

\section{Data Analysis}

Responses at both timepoints were inspected to identify potential outliers, resulting in the removal of one participant who reported participating 30 days in the past 30 days in all 27 participation areas, which was viewed as implausible. Paired sample $t$-test were conducted to examine the difference in continuous variables between Time 1 and Time 2. Cohen's Kappa and concordance rates were examined for categorical variables-responses regarding the perceived importance of the activity area and perceived sufficiency of their participation.

\section{Results}

\section{Sample Characteristics}

A total of 253 individuals completed the TUCP at both timepoints. Approximately two-thirds of the sample were men $(67 \%, \mathrm{n}=82)$ and the median age category was 40 to 49 . Additional sample characteristics are shown in Table 1.

\section{Test-Retest Reliability Findings}

Paired samples t-test results for scale scores and the amount of participation on individual items are presented in Table 2. No significant difference between Time 1 and Time 2 were detected on four out of five participation scales: Participation amount ( $t=-0.44, d f=209, p=0.664)$; number of important activity areas $(t=-0.62, d f=193, p=0.538)$; breadth ratio $(t=0.11, d f=167, p=0.912)$; and participation sufficiency $(t=-1.79, \quad d f=174$, $p=0.076)$. Significant Time 1 to 2 differences were found for breadth of participation scale $(t=-2.12$, $d f=194, p=0.035)$, although the difference was small (Cohen's $d=0.113$ ). At the individual item level for amount of participation, Time 1 to 2 differences were found on only one out of 27 items, visiting or inviting family $(t=-2.19, d f=206$, $p=0.030$ ), which could have been due to chance.

The responses on the importance of each participation area (i.e., Item rated as "Important" or "Not important") between Time 1 and Time 2 were highly concordant, with a range of $77 \%$ and $93 \%$ (median $=84 \%)$ and acceptable Cohen's Kappa values 
Table 1 Sample characteristics

\begin{tabular}{|c|c|c|c|}
\hline & \multicolumn{2}{|l|}{$\mathrm{n}$} & $\%$ \\
\hline \multicolumn{4}{|l|}{ Gender } \\
\hline Female & \multicolumn{2}{|l|}{82} & 32.4 \\
\hline Male & \multicolumn{2}{|l|}{170} & 67.2 \\
\hline Missing & \multicolumn{2}{|l|}{1} & 0.4 \\
\hline \multicolumn{4}{|l|}{ Age category } \\
\hline 20 to 29 & \multicolumn{2}{|l|}{27} & 10.7 \\
\hline 30 to 39 & \multicolumn{2}{|l|}{54} & 21.3 \\
\hline 40 to 49 & \multicolumn{2}{|l|}{85} & 33.6 \\
\hline 50 to 59 & \multicolumn{2}{|l|}{60} & 23.7 \\
\hline 60 to 69 & \multicolumn{2}{|l|}{19} & 7.5 \\
\hline 70 or above & \multicolumn{2}{|l|}{4} & 1.6 \\
\hline Missing & \multicolumn{2}{|l|}{4} & 1.6 \\
\hline \multicolumn{4}{|c|}{ The frequency of CESC use in the past 30 days } \\
\hline 0 day & \multicolumn{2}{|l|}{1} & 0.4 \\
\hline 1 to 3 days & \multicolumn{2}{|l|}{14} & 5.5 \\
\hline 4 to 6 days & \multicolumn{2}{|l|}{13} & 5.1 \\
\hline 7 to 9 days & \multicolumn{2}{|l|}{21} & 8.3 \\
\hline 10 to 12 days & \multicolumn{2}{|l|}{36} & 14.2 \\
\hline 13 to 15 days & \multicolumn{2}{|l|}{27} & 10.7 \\
\hline 16 days or more & 133 & & 52.6 \\
\hline & & Mean & SD \\
\hline Monthly allowanc & ation & 16,593 yen & 14,974 \\
\hline
\end{tabular}

$(\mathrm{k}=0.402-0.811)$. Similarly, satisfactory concordance between the timepoints on participation sufficiency (i.e., participation in the area done enough, not enough, or too much) was also found (73-88\%) along with satisfactory Cohen's Kappas $(\mathrm{k}=0.404-0.757)$.

Additional Findings About Importance and Sufficiency of Participation

These results also provide insights about the participation interests and experiences of this population. Using Time 1 results, we found that more than $50 \%$ of respondents indicated that five areas were particularly important to them: shopping for leisure $(\mathrm{n}=192$, $85 \%)$, working for pay $(\mathrm{n}=172,80 \%)$, using public transportation ( $\mathrm{n}=149,69 \%)$; going to a restaurant or coffee shop $(\mathrm{n}=132,60 \%)$, and going to a barber shop for leisure $(\mathrm{n}=125,58 \%)$. The bottom three areas of importance were going to watch sport event ( $\mathrm{n}=43,20 \%$ ), engaging in an organized sport $(\mathrm{n}=39,18 \%)$, and engaging in civic activities ( $\mathrm{n}=38,18 \%)$. Overall, the percentage of individuals who viewed each area as important is generally much lower than what has been found in other research (e.g. [29]).

Among those who indicated the activity area as important, the percentage who reported that they participated enough was highest for shopping for leisure (87\%), using public transportation (77\%), working for pay $(76 \%)$, and going to a barber shop (74\%). There were a number of areas that were important to respondents, but where sufficiency of participation was only $50 \%$ or lower, including meeting with friends (48\%), going to a gym $(40 \%)$, volunteering $(48 \%)$, hanging out and socializing with others $(50 \%)$, and the lowest scores for watching a sport event (37\%), going to school for degree (34\%), and going to a zoo or botanical garden (34\%) (Table 3).

\section{Discussion}

Study results demonstrated that the Temple University Community Participation could be successfully translated into Japanese and produce consistent test-retest responses. Despite concerns about cognitive impairments experienced by some with significant mental health issues [34], especially with episodic memory and meta-cognition, these results suggest that Japanese participants with significant mental health issues can provide reliable answers about their participation and interests on the scale scores and on individual items. These results for the TUCP-J are consistent with previous reliability findings on the English version [27, 29].

The successful translation of this measure and finding that it has good test-retest reliability is a major advance in fulfilling calls for increased attention to community participation in Japan [20, 21]. The TUCP-J could reasonably be used to develop a better understanding of an individual's current participation and interests, as well as assist in evaluating outcomes associated with programs like ACT [24, 25] and peer support programs [26]. The findings also suggest that the construct of community participation, at least as measured using the TUCP, may be similarly assessed 
Table 2 Summary of paired t-tests, examining differences in scores between Time 1 and Time 2 administration

\begin{tabular}{|c|c|c|c|c|c|c|c|c|c|}
\hline \multirow[b]{2}{*}{ Variable } & \multicolumn{3}{|c|}{ Time 1} & \multicolumn{3}{|c|}{ Time 2} & \multicolumn{3}{|c|}{ Paired T-Test } \\
\hline & $\mathrm{n}$ & Mean & SD & $\mathrm{n}$ & Mean & SD & $t$ & $d f$ & $p$ \\
\hline \multicolumn{10}{|l|}{ Number of participation days } \\
\hline Go shopping for leisure & 213 & 11.52 & 9.93 & 213 & 11.91 & 10.30 & -0.88 & 212 & .3791 \\
\hline Work for pay & 207 & 10.93 & 8.56 & 207 & 10.89 & 8.33 & 0.07 & 206 & .9482 \\
\hline Use public transportation & 210 & 6.71 & 8.78 & 210 & 6.32 & 8.53 & 1.06 & 209 & .2919 \\
\hline Play game at their own home & 211 & 4.10 & 9.18 & 211 & 3.42 & 8.65 & 1.7 & 210 & .0907 \\
\hline Go to a restaurant or coffee shop & 209 & 2.73 & 4.69 & 209 & 2.67 & 4.56 & 0.23 & 208 & .8154 \\
\hline Go to a park or recreation center & 209 & 1.40 & 3.84 & 209 & 1.84 & 4.87 & -1.88 & 208 & .0614 \\
\hline Spending time with family at home & 207 & 0.92 & 3.56 & 207 & 1.38 & 4.57 & -2.19 & 206 & .0299 \\
\hline Socialize with people from work/school/etc & 209 & 0.84 & 3.48 & 209 & 1.20 & 4.48 & -1.88 & 208 & .0615 \\
\hline Play games outside the home & 210 & 0.70 & 3.71 & 210 & 0.52 & 2.78 & 0.74 & 209 & .4588 \\
\hline Spending time with friends at home & 212 & 0.69 & 2.76 & 212 & 0.75 & 2.87 & -0.65 & 211 & .5140 \\
\hline Go to a library & 211 & 0.57 & 1.93 & 211 & 0.55 & 1.75 & 0.39 & 210 & .6946 \\
\hline Go to a barber shop & 209 & 0.57 & 1.62 & 209 & 0.60 & 1.42 & -0.23 & 208 & .8157 \\
\hline Go to a gym & 211 & 0.38 & 2.77 & 211 & 0.40 & 2.97 & -0.12 & 210 & .9060 \\
\hline Engage in volunteering & 210 & 0.34 & 2.28 & 210 & 0.53 & 2.59 & -1.01 & 209 & .3117 \\
\hline Go to a movie & 211 & 0.25 & 0.79 & 211 & 0.27 & 0.94 & -0.43 & 210 & .6693 \\
\hline Go to a place of worship & 214 & 0.24 & 1.03 & 214 & 0.26 & 1.13 & -0.54 & 213 & .5912 \\
\hline Go to a social group in the community & 210 & 0.24 & 1.49 & 210 & 0.14 & 0.63 & 0.97 & 209 & .3337 \\
\hline Engage in civic activities & 207 & 0.22 & 2.13 & 207 & 0.10 & 0.59 & 0.81 & 206 & .4214 \\
\hline Go to a community event & 209 & 0.14 & 0.86 & 209 & 0.16 & 0.88 & -0.67 & 208 & .5063 \\
\hline Go to a theater or cultural event & 211 & 0.11 & 0.55 & 211 & 0.15 & 0.60 & -0.9 & 210 & .3714 \\
\hline Attend a community event with family & 211 & 0.06 & 0.30 & 211 & 0.12 & 0.79 & -1.07 & 210 & .2847 \\
\hline Attend a community event with friends & 210 & 0.06 & 0.32 & 210 & 0.11 & 0.75 & -0.95 & 209 & .3450 \\
\hline Go to a zoo or botanical garden & 210 & 0.06 & 0.32 & 210 & 0.04 & 0.23 & 0.77 & 209 & .4399 \\
\hline Go to watch a sport event & 211 & 0.06 & 0.45 & 211 & 0.04 & 0.38 & 1.42 & 210 & .1578 \\
\hline Take a class for leisure & 211 & 0.03 & 0.24 & 211 & 0.05 & 0.30 & -1 & 210 & .3185 \\
\hline Engage in an organized sport & 210 & 0.02 & 0.19 & 210 & 0.04 & 0.44 & -0.78 & 209 & .4362 \\
\hline Go to school for degree & 211 & 0.02 & 0.23 & 211 & 0.13 & 1.11 & -1.43 & 210 & .1550 \\
\hline \multicolumn{10}{|l|}{ Participation scales } \\
\hline Participation amount & 210 & 42.95 & 29.39 & 210 & 43.54 & 29.32 & -0.44 & 209 & .6636 \\
\hline Number of important activities & 194 & 9.98 & 7.09 & 194 & 10.19 & 7.08 & -0.62 & 193 & .5376 \\
\hline Breadth of participation & 195 & 4.18 & 3.02 & 195 & 4.52 & 2.98 & -2.12 & 194 & .0349 \\
\hline Breadth ratio & 168 & 0.56 & 0.32 & 168 & 0.56 & 0.32 & 0.11 & 167 & .9117 \\
\hline Sufficiency & 175 & 0.56 & 0.34 & 175 & 0.60 & 0.33 & -1.79 & 174 & .0760 \\
\hline
\end{tabular}

in both Western and non-Western countries (e.g., Japan). Most current research on community participation among individuals with mental illnesses have been conducted in Western countries.

While evidence of test-retest reliability was observed in nearly all areas, there was a difference on one scale - breadth of participation, and on the item about number of days they visited family. The five consumers who provided feedback on the measure during the translation process indicated that they had never been asked about their community participation interests in such a thorough way before and that the 
Table 3 Importance and sufficiency of community participation at Time 1

\begin{tabular}{|c|c|c|c|c|c|c|c|c|}
\hline \multirow[b]{3}{*}{ Variable } & \multicolumn{8}{|c|}{ Out of those who say area is important report engaging in area... } \\
\hline & \multicolumn{2}{|c|}{ Important } & \multicolumn{2}{|c|}{ Not enough } & \multicolumn{2}{|c|}{ Enough } & \multicolumn{2}{|c|}{ Too much } \\
\hline & $\mathrm{N}$ & $\%$ & $\mathrm{~N}$ & $\%$ & $\mathrm{~N}$ & $\%$ & $\mathrm{~N}$ & $\%$ \\
\hline Go shopping for leisure & 192 & 84.96 & 20 & 10.58 & 164 & 86.77 & 5 & 2.65 \\
\hline Work for pay & 172 & 80.00 & 37 & 22.84 & 123 & 75.93 & 2 & 1.23 \\
\hline Use public transportation & 149 & 68.98 & 30 & 21.28 & 109 & 77.30 & 2 & 1.42 \\
\hline Go to a restaurant or coffee shop & 132 & 60.27 & 44 & 34.38 & 83 & 64.84 & 1 & 0.78 \\
\hline Go to a barber shop & 125 & 57.87 & 32 & 26.45 & 89 & 73.55 & 0 & 0.00 \\
\hline Spend time with friends at home & 92 & 43.60 & 45 & 51.14 & 42 & 47.73 & 1 & 1.14 \\
\hline Go to a library & 92 & 42.99 & 50 & 54.35 & 42 & 45.65 & 0 & 0.00 \\
\hline Spend time with family at home & 89 & 42.18 & 31 & 36.90 & 51 & 60.71 & 2 & 2.38 \\
\hline Go to a park or recreation center & 86 & 40.19 & 31 & 36.90 & 52 & 61.90 & 1 & 1.19 \\
\hline Socialize with people from work/school/etc & 81 & 38.03 & 36 & 47.37 & 38 & 50.00 & 2 & 2.63 \\
\hline Engage in volunteering & 76 & 36.02 & 36 & 49.32 & 35 & 47.95 & 2 & 2.74 \\
\hline Go to a movie & 78 & 35.94 & 38 & 51.35 & 36 & 48.65 & 0 & 0.00 \\
\hline Go to a theater or cultural event & 72 & 33.49 & 38 & 53.52 & 33 & 46.48 & 0 & 0.00 \\
\hline Play game at their own home & 71 & 32.87 & 19 & 28.36 & 44 & 65.67 & 4 & 5.97 \\
\hline Go to a gym & 67 & 31.16 & 38 & 58.46 & 26 & 40.00 & 1 & 1.54 \\
\hline Go to a zoo or botanical garden & 65 & 30.23 & 42 & 65.63 & 22 & 34.38 & 0 & 0.00 \\
\hline Go to school for degree & 62 & 28.70 & 40 & 65.57 & 21 & 34.43 & 0 & 0.00 \\
\hline Attend a community event with friends & 60 & 28.44 & 28 & 48.28 & 30 & 51.72 & 0 & 0.00 \\
\hline Attend a community event with family & 59 & 27.70 & 25 & 43.86 & 32 & 56.14 & 0 & 0.00 \\
\hline Go to a social group in the community & 58 & 27.49 & 25 & 45.45 & 30 & 54.55 & 0 & 0.00 \\
\hline Go to a place of worship & 56 & 26.17 & 19 & 35.19 & 34 & 62.96 & 1 & 1.85 \\
\hline Play games outside the home & 55 & 25.70 & 21 & 39.62 & 32 & 60.38 & 0 & 0.00 \\
\hline Go to a community event & 54 & 25.23 & 19 & 36.54 & 33 & 63.46 & 0 & 0.00 \\
\hline Take a class for leisure & 47 & 22.07 & 24 & 52.17 & 22 & 47.83 & 0 & 0.00 \\
\hline Go to watch a sport event & 43 & 20.00 & 26 & 63.41 & 15 & 36.59 & 0 & 0.00 \\
\hline Engage in an organized sport & 39 & 18.14 & 21 & 56.76 & 16 & 43.24 & 0 & 0.00 \\
\hline Engage in civic activities & 38 & 18.01 & 13 & 36.11 & 23 & 63.89 & 0 & 0.00 \\
\hline
\end{tabular}

questions made them reflect on it much more than they had previously. It is plausible that the difference on breadth of participation resulted from their paying increased attention to what they are doing between Time 1 and Time 2, although no differences were found on the other scales where such attention might also make a difference. The inconsistent finding on visiting with family could simply be due to chance (i.e., one out of 27 tests was statistically significant).

The results also provide insights on the current community participation among a sub-group of Japanese with serious mental illnesses (SMI). Study results indicate that only five areas were rated as important by more than $50 \%$ of respondents, which is strikingly low compared to one study conducted in the United States, where more than $50 \%$ of respondents rated 16 areas as important [29]. This could have been an indicator of cross-cultural incompatibility of the items, but the Japanese translators, program staff, and advisory group of consumers all believed the participation items covered on the TUCP-J were important to Japanese people. It is possible that respondents in this study had more severe impairments, including negative symptoms, based on the type of program they 
were recruited from compared to the fairly heterogenous sample of individuals in the U.S. study, resulting in their reporting of fewer interests. The relative lack of important areas could also reflect adaptive preferences [35], whereby respondents may not indicate some areas as important because they have been discouraged from participating in them or had failure experiences while previously participating [36]. For example, they may receive messages, both implicit and explicit, about challenges they will face in obtaining competitive employment and possibly engagement in other participation areas [37]. Limited participation opportunities while receiving institutional care [38] may have also led some to never develop a broad-range of interests.

Japanese respondents had similar level of interests in certain activities such as shopping, and working for pay, as was found in the U.S. sample. However, they differed significantly in other areas. For example, only $26 \%$ of the Japanese participants reported interests in activities related to worshipping, but most (78\%) participants showed interests in worshipping in the US sample [29]. This might reflect different spiritual practices, as Americans go to places like churches or other places of worship while many Japanese engage in unchurched spiritual practices such as meditation [39]. It may be that the Shinto ban following World War II and cult terrorism in 1995 led Japanese people to avoid explicit religious practices [40]. Similarly, many respondents in this study did not consider civic and political activities as important, possibly because it has been observed that political participation and civic engagement among Japanese has been inactive for decades [41], possibly due to their unwillingness to get involved in the activities that might express their political stance [42].

Sufficiency of participation was relatively high in some important areas, such as shopping, use of public transportation, and work for pay, the latter not being surprising because all participants were recruited from employment programs. There were also a number of areas that were important to respondents, but where they believed they did not participate enough. This includes spending time with friends or others, where about $50 \%$ of participants indicated not doing enough, as well as leisure activities, such as going to a move or cultural activity, watching a sports event, or taking a class for leisure, as well as volunteering.
There are a number of implications from this study. The results suggest that the TUCP-J is a reliable measure with a very impaired SMI subgroup and could be used with broader group in future research. The limited number of highly important areas that were reported point to a number of possible directions, including addressing barriers people may face in their attempts to participate in the community, such as reducing prejudice and discrimination and providing community-based participation supports, to reduce possible adaptive preferences. Type-B CESCs could also spend more time speaking with program participants about their interests and encouraging participation in a broad-range of areas. Finally, efforts could be made to also address individual skills required for successful participation in areas that are important to them and addressing environmental barriers they may face (e.g., stigma, costs, transportation, lack of social support) in those areas. It should be noted, however, that the data were gathered during the COVID-19 pandemic, which could have impacted results. It is plausible that ratings about importance and sufficiency could have been impacted by the closure of an activity venue or because of not wanting to leave the home due to fear of infection.

\section{Limitations}

While the current study was quite informative, there are a few limitations to be acknowledged. First, although all the participants were recruited from the same type of program (i.e., Type-B CESCs) that has fairly prescriptive requirements for enrollment of those with among the most impairments, individual diagnostic information was not collected. While the level of functioning should be quite homogeneous, this limited our ability to fully describe the diagnostic composition of the sample, which may or may not have impact on participation results. Another limitation is some degree of selection bias. Program staff encouraged all the service users to participate, and $72 \%$ did participate, but it is unclear whether the other $28 \%$ differed in some important way from the others. Finally, as mentioned above, data collection took place during public health measures associated with the COVID-19 pandemic and some community activities such as sporting events, festivals, and social gathering were restricted. This will serve as an 
interesting point of comparison for future research when restrictions are lessened.

\section{Conclusion}

This study found good evidence of test-retest reliability for the Japanese version of the Temple University Community Participation measure (TUCP-J). Such a measure can be useful in Japan as policies and services continue to advance in the promotion of community inclusion of individuals with SMI and move away from institutional care. The results also suggest a possible need to attend to the relatively few areas that are viewed as important to these respondents and possible reasons for that. It also draws attention to the notion of sufficient participation-doing enough in important areas, and structuring future supports and services to assisting Japanese citizens with SMI to engage fully in areas that are important to them as a rights issue and a matter of health promotion.

Acknowledgements The authors would like to thank the study participants at Type-B Continuous Employment Support Centers in Japan.

Funding The study was a part of the national study funded by the Ministry of Health, Labor, and Welfare in Japan for the fiscal year of 2019 and 2020, "The state-of-the-art work support centers Type B for individuals with psychiatric disabilities and developing the best practice" (19GC0601; PI: Jun Yaeda).

\section{Declarations}

Conflict of interest The authors declare that they have no known competing financial interests or personal relationships that could have appeared to influence the work reported in this paper.

Ethical approval This study was approved by the University of Tsukuba, Faculty of Human Science IRB: Protocol \# East 2020-82.

\section{References}

1. The United Nations. Convention on the rights of persons with disabilities. Treaty Ser. 2006;2515:3.

2. Salzer MS. Community inclusion and social determinants: from opportunity to health. Psychiatr Serv. 2021;72(7):836-9. https://doi.org/10.1176/appi.ps. 202000394.

3. Salzer MS, Nagata S. Community inclusion as a human right and medical necessity for individuals with serious mental illnesses. Clin Psychiatry/Seishin-Igaku. 2021;63(7):1123-35. https://doi.org/10.11477/mf. 1405206411 (Japanese).

4. World Health Organization (2001) international classification of functioning, disability, and health (ICF). World Health Organization

5. Burns-Lynch B, Brusilovskiy E, Salzer MS. An empirical study of the relationship between community participation, recovery, and quality of life of individuals with serious mental illnesses. Isr J Psychiatry Relat Sci. 2016;53(1):46.

6. Kaplan K, Salzer MS, Brusilovskiy E. Community participation as a predictor of recovery-oriented outcomes among emerging and mature adults with mental illnesses. Psychiatr Rehabil J. 2012;35(3):219.

7. Snethen G, Brusilovskiy E, McCormick BP, Hiremath SV, Salzer MS. The relationship between community participation and physical activity among individuals with serious mental illnesses. Ment Health Phys Act. 2021;20:100381.

8. Nagata S, McCormick B, Brusilovskiy E, Salzer MS. Community participation as a predictor of depression among individuals with serious mental illnesses: a longitudinal analysis. Int J Soc Psychiatry. 2021. https://doi.org/ 10.1177/00207640211052182.

9. Nagata S, McCormick B, Brusilovskiy E, Snethen G, Townley G, Salzer MS. Depressive symptoms and community participation among individuals with serious mental illnesses. Am J Orthopsychiatry. 2021;91(5):598-606.

10. Nagata S, McCormick B, Brusilovskiy E, Zisman-Ilani Y, Wilson S, Snethen G, Townley G, Salzer MS. Emotional states associated with being in the community and being with others among individuals with serious mental illnesses. Am J Orthopsychiatry. 2021;91(1):1.

11. Ding N, Berry HL, O'Brien LV. One-year reciprocal relationship between community participation and mental wellbeing in Australia: a panel analysis. Soc Sci Med. 2015;128:246-54.

12. Huebner RA, Johnson K, Bennett CM, Schneck C. Community participation and quality of life outcomes after adult traumatic brain injury. Am J Occup Ther. 2003;57(2):177-85.

13. Corrigan PW, Phelan SM. Social support and recovery in people with serious mental illnesses. Community Ment Health J. 2004;40(6):513-23.

14. Davidson L, Borg M, Marin I, Topor A, Mezzina R, Sells D. Processes of recovery in serious mental illness: findings from a multinational study. Am J Psychiatric Rehabil. 2005;8(3):177-201.

15. Schön UK, Denhov A, Topor A. Social relationships as a decisive factor in recovering from severe mental illness. Int J Soc Psychiatry. 2009;55(4):336-47.

16. World Health Organization (2021) Guidance on community mental health services: Promoting person-centered and rights-based approaches. World Health Organizations

17. Nagata S, Townley G, Brusilovskiy E, Salzer MS. Community participation differences between adults with or without serious mental illness. Psychiatr Serv. 2020;71(11):1191-4.

18. Ministry of Health, Labour and Welfare (2009) Kongo no seishin hoken iryo fukushi no arikata tou ni kansuru kentoukai ni tsuite [Discussion on the direction of mental health care and welfare]. Ministry of Health, Labour and Welfare 
of Japan. Retrieved from http://www.mhlw.go.jp/shingi/ 2009/09/dl/s0924-2a.pdf

19. Yamashita Y, Yabuta A, Iseki T. Tiiki teichaku wo jisshi suru shiensya no ninshiki suru seishin syougaisya ga tiiki de kurasu tameni hitsuyo na youso [Elements that supporters who take root community support recognize as necessary for people with mental disability to live in a local community]. J Jpn Acad Psychiatr Ment Health Nurs. 2018;27(1):82-90.

20. Sakai I, Mizuno E. Tiiki de seikatsu suru seishin shogaisya no ikigai no tokucho [Purpose of life of people with mental illness living in the community. J Jpn Acad Nurs Sci. 2011;31(3):32-41.

21. Tsuzumi M, Tsuji Y, Nishii M, Izuta M, Sukeno O. Bunken kenkyu kara miru seishin syogaisya no tiiki seikatsu shien no kadai ni kansuru kousatsu [Consideration of issues related to the support of the community life of mentally ill people based on a literature survey]. Sougou Fukushi Kagaku Kenkyu. 2012;3:175-86.

22. Hayashi T, Yamaguchi S, Sato S. Implementing the individual placement and support model of supported employment in Japan: barriers and strategies. Psychiatr Rehabil J. 2020;43(1):53.

23. Oshima I, Sono T, Bond GR, Nishio M, Ito J. A randomized controlled trial of individual placement and support in Japan. Psychiatr Rehabil J. 2014;37(2):137.

24. Horiuchi K, Nisihio M, Oshima I, Ito J, Matsuoka H, Tsukada K. The quality of life among persons with severe mental illness enrolled in an assertive community treatment program in Japan: 1-year follow-up and analyses. Clin Pract Epidemiol Ment Health. 2006;2(1):1-7.

25. Ito J, Oshima I, Nishio M, Sono T, Suzuki Y, Horiuchi K, Niekawa N, Ogawa M, Setoya Y, Hisanaga F, Kouda M. The effect of assertive community treatment in Japan. Acta Psychiatr Scand. 2011;123(5):398-401.

26. Yokoyama K, Miyajima R, Morimoto T, Ichihara-Takeda S, Yoshino J, Matsuyama K, Ikeda N (2021) Peer support formation and the promotion of recovery among people using psychiatric day care in Japan. Community Ment Health J 1-9

27. Salzer MS, Kottsieper P, Brusilovskiy E. Intermethod reliability and factors affecting recall with the Temple University Community participation measure. J Ment Health. 2015;24(4):189-95.

28. Üstün TB, Chatterji S, Bickenbach J, Kostanjsek N, Schneider M. The international classification of functioning, disability and health: a new tool for understanding disability and health. Disabil Rehabil. 2003;25(11-12):565-71.

29. Salzer MS, Brusilovskiy E, Prvu-Bettger J, Kottsieper P. Measuring community participation of adults with psychiatric disabilities: reliability of two modes of data collection. Rehabil Psychol. 2014;59(2):211-9. https://doi.org/10. 1037/a0036002.

30. Perenboom RJ, Chorus AM. Measuring participation according to the international classification of functioning, disability and health (ICF). Disabil Rehabil. 2003;25(11-12):577-87.

31. Brislin RW. Back-translation for cross-cultural research. J Cross Cult Psychol. 1970;1(3):185-216.

32. Ministry of Health, Labour and Welfare (2013) Tiiki shakai ni okeru kyosei no jitsugen ni mukete aratana shogai hoken fukushi shisaku wo kouzuru tameno kankei houritsu no seibi ni kansuru houritsu [Comprehensive Services and Supports for Persons with Disabilities Act]. Ministry of Health, Labour and Welfare of Japan. http://www.mhlw.go.jp/ seisakunitsuite/bunya/hukushi_kaigo/shougaishahukushi/ sougoushien/d1/sougoushien-02.pdf

33. Marx RG, Menezes A, Horovitz L, Jones EC, Warren RF. A comparison of two time intervals for test-retest reliability of health status instruments. $J$ Clin Epidemiol. 2003;56(8):730-5.

34. Millan MJ, Agid Y, Brüne M, Bullmore ET, Carter CS, Clayton NS, Connor R, Davis S, Deakin B, DeRubeis RJ, Dubois B. Cognitive dysfunction in psychiatric disorders: characteristics, causes and the quest for improved therapy. Nat Rev Drug Discov. 2012;11(2):141-68.

35. Babulal GM, Bakhshi P, Kopriva S, Ali SA, Goette SA, Trani JF. Measuring participation for persons with mental illness: a systematic review assessing relevance of existing scales for low and middle income countries. BMC Psychol. 2015;3(1):1-10.

36. Kasahara-Kiritani M, Matoba T, Kikuzawa S, Sakano J, Sugiyama K, Yamaki C, Mochizuki M, Yamazaki Y. Public perceptins toward mental illness in Japan. Asian J Psychiatr. 2018;35:55-60.

37. Miyadi A (2015) Seishin syogaisya no stigma seisei no kijyo ni kansuru kenkyu [A mechanism for generation of stigma toward mental illness]. Doctoral dissertation, Kagoshima International University. CiNii Dissertation Database

38. Kanata T. Japanese mental health care in historical context: Why did Japan become a country with so many psychiatric care beds? Soc Work. 2016;52(4):471-89.

39. Stark R, Hamberg E, Miller AS. Exploring spirituality and unchurched religions in America, Sweden, and Japan. J Contemp Relig. 2005;20(1):3-23.

40. Kobayashi T. Nihonjin no syukyo teki ishiki ha dou kawattaka [How have japanese attitudes and behavior on religion changed?]. NHK Mon Rep Broadcast Res. 2019;69(4):52-72.

41. Hirano H. Nihon ni okeru seiji bunka to shimin sanka [Civic participation and political culture in Japan]. Seisaku Kagaku. 2012;19(3):143-61.

42. Nishizawa Y. Seiji sanka no niju kozo to 'Kakawari-takunai' Ishiki [Retreating democracy: a puzzle of political participation in Japan]. Doshisha Hougaku. 2004;55(5):1215-43.

Publisher's Note Springer Nature remains neutral with regard to jurisdictional claims in published maps and institutional affiliations. 